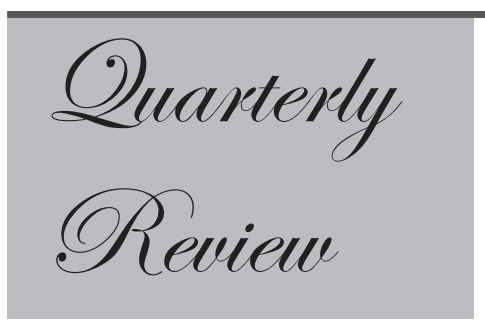

${ }^{1}$ Consultant Surgical Gastroenterologist, Apollo Speciality Hospitals, Lake View

Road, KK Nagar, Madurai-625020, Tamil Nadu, India.

${ }^{2}$ Research Fellow, Department of Psychiatry, Cleveland Clinic Foundation, 9500, Euclid avenue, Cleveland,

Ohio 44106.

${ }^{3}$ ESIC Medical College and Post Graduate Institute of Medical Science and Research, Bangalore, Karnataka, India.

${ }^{4}$ Resident physician, Department of Internal Medicine, Cleveland Clinic Foundation, 9500, Euclid avenue, Cleveland, Ohio 44106.

Correspondence: Madhusudhanan Jegadeesan Email:doctorjmadhu@gmail.com

\section{Glimpses into the history of upper gastrointestinal surgeons: pearls for the present day surgeon}

\author{
Madhusudhanan Jegadeesan ${ }^{1}$,Tharani Sundararajan ${ }^{2}$, \\ Jyothimani Selvaraj $^{3}$, Ramprasad Jegadeesan ${ }^{4}$
}

\section{ABSTRACT}

The great Roman philosopher Cicero once said, 'To know nothing of what happened before you were born is to forever remain a child'. To climb the tower of a scientific discipline, we should realize how the tower was built. A surgeon faces innumerable problems throughout his career that affects both his personal and professional life. We always believe the answers to problems of the present day lie in the pages of the past. In the glimpses of great moments in the career of a few extraordinary surgeons, we attempt to bring to the fore their treasure trove of knowledge, learning, heroism and devotion along with the relevance their persona holds to the present day surgeon.

KEYWORDS: Upper Gastrointestinal surgery, Surgeon, History
A little less than two centuries ago, Theodor Billroth was persuaded to take up medicine for pecuniary reasons, despite his interests in music. ${ }^{1}$ After graduation, his attempts to set up a general practice in Berlin failed and he became an assistant to Bernhard von Langenbeck in the surgical clinic at the Berlin University. These early years of Billroth, in the mid-19th Century, is no different from the situation an average medical student will face today.

During his early years at University of Göttingen, he found friendship in George Meissner and pursued methodical studies on pathology under Ludwig Traube. The events that took place in the later years of Billroth's life were set to open a new arena in the field of surgery. None of them occurred by chance. For instance, it took multiple anatomical and physiological experiments by him and his students to understand a fact that we take for granted in

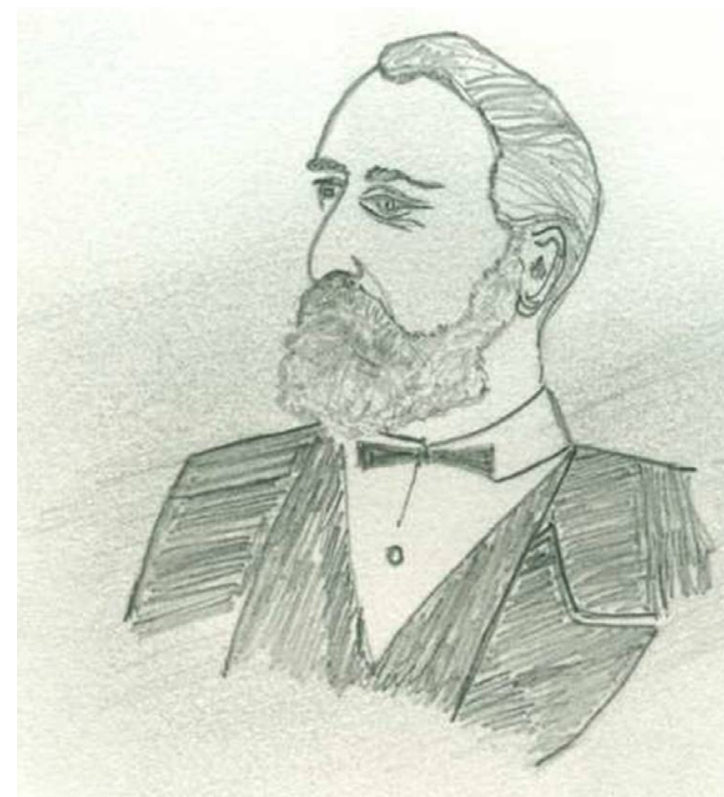

Theodor Billroth ( 1829-1894) 
the present day: the stomach can be resected and can be diverted to directly empty into the jejunum. ${ }^{2}$ Legend has it that he was nearly stoned to death in the streets after his initial unsuccessful attempts at gastrectomy. Billroth did not have the modern 'luxury' of legal proceedings or medical lawsuits. If a surgeon had a firm belief built on sound scientific experiments and principles, trials and tribulations could not deter him from further pursuit.

Theodor Billroth recorded all his cases meticulously and published the same without regard to the results. More than a century ago, he was probably the first to conduct mortality and morbidity meetings. He encouraged honest discussion among surgeons, which is reminiscent of the multidisciplinary team meetings of the present day, as there were hardly any other specialties. Thus, he laid the foundation for surgical audits. He envisioned evidence-based surgical practice much ahead of his times. Hence, he is rightly called the Father of Academic Surgery. Following in his footsteps, abudding young surgeon should take the effort to devote enough time to record-keeping, which aids both introspection and retrospection.

A great teacher does not make a great student, rather he creates another great teacher. Billroth sent his students for academic pursuits to other institutions across Europe, another radical idea in the late 19th Century. On one such trip, his luminous student, Jan MikuliczRaedecki met Joseph Lister and brought back to Vienna, the principles of antisepsis in surgical practice. Infection was killing as many as half of the patients undergoing major surgeries during that time. Many surgeons and physicians from all over the world who went to Germany brought back to their country the doctrines of aseptic practices like sterilizing instruments, wearing masks, gloves and gowns. ${ }^{3}$ For the first time ever, surgery became safer. This stands testimony to the principle that a surgeon should endeavor to take frequent trips to universities in different parts of the world. This ensures rapid globalisation of surgical techniques and serves the greater purpose of benefiting the community.

Great minds think alike. Billroth's ideals can be appreciated by his saying, “"It is one of the superficialities of our time to see in science and in art two opposites. Imagination is the mother of both." Albert Einstein says," I am enough of an artist to draw freely upon my imagination. Imagination is more important than knowledge. Knowledge is limited. Imagination encircles the world." ${ }^{4}$ Modern medicine is replete with scientific content which has the potential of converting doctors into systemized robots. However, a surgeon should nurture and cultivate his imagination skills not solely to enjoy his art but also to look at it from a different perspective.

Imagination is the mother of innovation. Billroth, as a chief surgeon succeeded in setting up an environment for research. It was during this period that Mikulicz devised a rigid gastroscope after long experiments. The present day endoscope is but a slight advancement from Mikulicz design which had an electric wire and two inner tubes for insufflating air and water. In the early years of 1880, Mikulicz writes, “...the future of the excision of the pylorus depends mainly on working out some method of early detection of gastric diseases. I hope that my gastroscope will also contribute to this, sooner or later". ${ }^{5}$ This path-breaking invention was going to change the course of upper gastrointestinal surgery forever. And with this prototype, other endoscopes for examining the colon, nasal cavity and the tracheobronchial tree were designed. A surgeon, as a student should engage actively in research and more importantly, when he assumes power, ought to facilitate research work.

After his term with Billroth, Mikulicz moved to Cracow and became the Professor and head of the Department of Surgery at Jagiellonian University. It was a small hospital with only 21 beds with an operation theatre which was used for dressing wounds and corpse demonstration. ${ }^{5}$ This instance is no different from a present day surgeon who may land up in a small hospital for their job after getting trained from a bigger institution. However, Mikulicz improvised it and started performing major surgeries and soon the department became one of the best centers in Poland.

After Cracow, Mikulicz became the head of the Surgical Department in Wroclaw by 1890 . He had set up basic science labs for biochemical, microbiological and pathological studies. His acquaintance with Lister led him to introduce the principles of antisepsis so rigorously that he even took cultures from surgeon's hands and surgical instruments to ensure asepsis. ${ }^{5}$ This department became 
world-renowned and attracted eminent personalities like Harvey Cushing, William and Charles Mayo from the United States and Mishigi Takayasu from Japan. The story of Jan Mikulicz-Raedecki, who devised the gastroscope as a student and transformed a small hospital into a knowledge powerhouse, does not end here.

In the early 1900s, tuberculosis was a major health problem resulting in 50\% mortality within five years even in a sanatoria. ${ }^{6}$ Surgery for thoracic tuberculosis was considered unsafe since opening the thorax resulted in collapse of the lungs and death. Mikulicz conceived the idea of operating in a low-pressure environment to avoid open pneumothorax. After a series of animal experiments, his student Ferdinand Sauerbruch designed a chamber which could maintain a negative pressure of $10 \mathrm{mmHg}$. This was first used for thorocotomy at Mikulicz' department in 1904 and later demonstrated at the German Congress for Surgery in Berlin. Later, Sauerbruch was appointed the head of the surgical department at the Charité in Berlin and became one of the most respected and highly esteemed thoracic surgeons in Europe. ${ }^{7}$ In 1908, he took his chamber to the US for the meeting of the American Medical Association and handed it over to Willy Meyer, who was a prominent thoracic surgeon in New York. Meyer improvised the design and created a 'universal pressure chamber' which was installed at the German Hospital (later renamed Lenox Hill Hospital) in New York in 1911 and was used for many thoracic surgeries. If Billroth opened the doors of Abdominal surgery, Mikulicz and Sauerbruch sowed the first seeds for yet another discipline: Thoracic Surgery.

Across the Atlantic, in the United Kingdom, another towering personality in the field of upper gastrointestinal surgery was Norman Barrett. Starting his illustrious surgical career at the St. Thomas Hospital, London, it is hard to believe his duty hours as a resident assistant surgeon for 2 years. He literally lived in the wards and as Ronald Belsey recalls, could barely manage 3 hours of sleep in a day. Even later in life, his busy professional life permitted him to spend only an hour on Sunday evenings with his two children. ${ }^{10}$ The present day surgeon should have no reason to deplore his own disposition.

As a young surgeon, Barrett was known to have
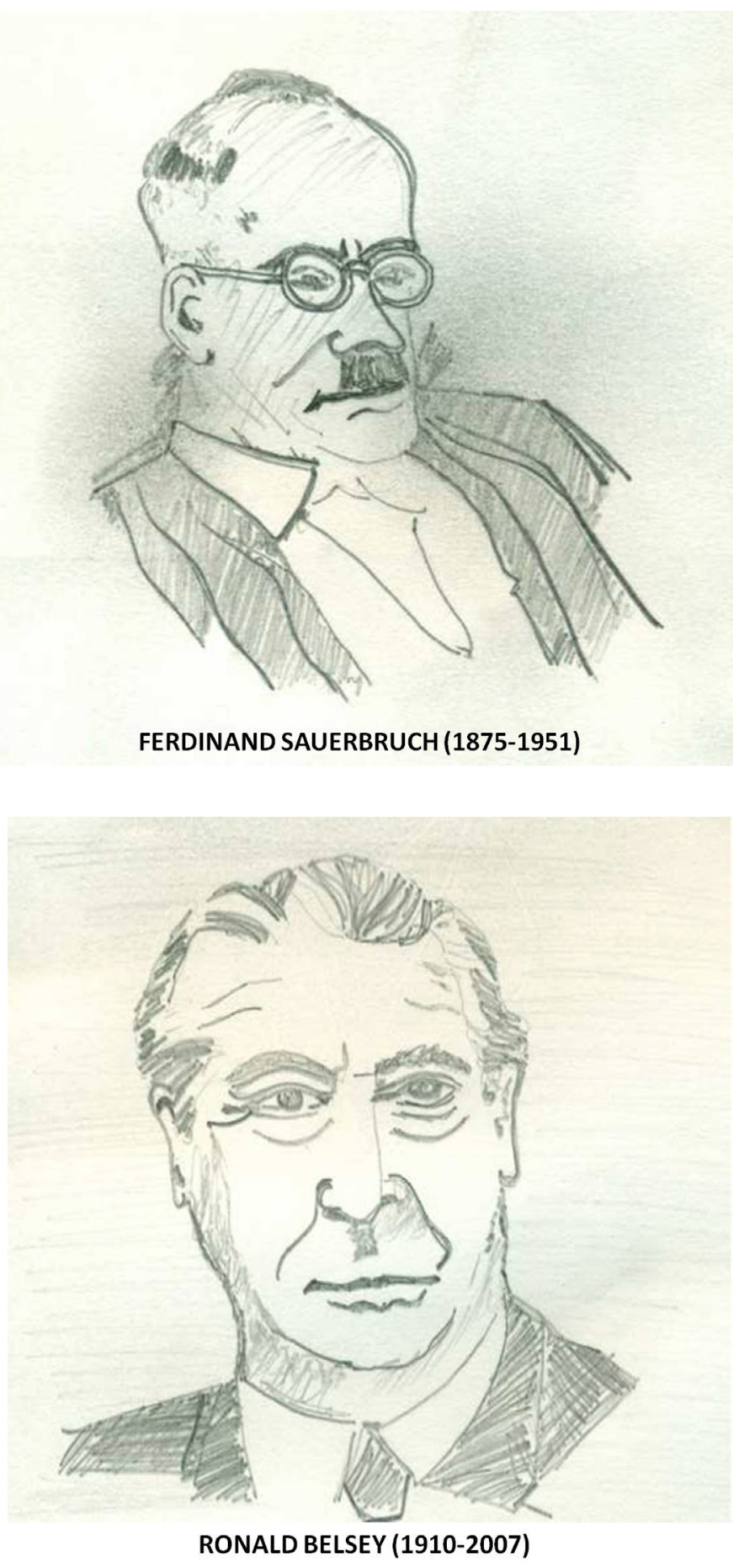

strong disregard for sham and a relentless search for truth. The thoroughness of his search to bring out an authentic scientific paper is outstanding and is evidenced by his 1950 article on foreign bodies in cardiovascular system which included 200 references. ${ }^{13}$ One can imagine the hardship involved in fetching data years before the computer, Internet and Pubmed came into existence. 
As the first surgical editor of the journal, Thorax, in the mid-1940s, he was known to go the extra mile to help a foreign author edit his paper to acceptable literary style if it contained material scientifically worth publishing.

In his 1962 paper entitled, 'Publish or Perish', he warns about the other side of scientific approach to surgery. ${ }^{11}$ Barrett says the knowledge gained by scientific surgical research should lay the path only to wisdom in clinical excellence and writes "... The ancients saw clearly - more clearly than we do - the necessity for dominating knowledge with wisdom." To elucidate further, he quotes a contemporary English philosopher Alfred North Whitehead to define wisdom, 'Wisdom is mastery of knowledge'. Billroth's emphasis on imagination and Barrett's theory on wisdom serve the sole purpose of drawing the line between the human doctor and the matrix of ever-accumulating scientific data. We should realize that this is a cry to save the surgeon from getting lost in the sea of knowledge.

Norman Barrett has been hailed by his colleagues to have a very pleasing and delightful personality. In an obituary for The Times, William Thomson writes "a pretty gift for cynicism, linked with a pleasing degree of disrespect for authority-or at least a joy in debunking it, combined with a gift for exposition, made him one of the best surgical teachers of his time. Heaven help any of his colleagues who tried to be pompous, but the learner in search of knowledge always found him accessible and clarity personified." ${ }^{12}$ As a surgeon ascends in his career, he should never lose the sweet demeanor he carried as a resident. His favorite sayings as recalled by his residents and colleagues were, "Never, under any circumstances, give way to the illusion that you are doing any good" and "When you make pronouncements, listen for the still small voice that whispers, 'fiddlesticks' ".

Years before teamwork in surgery became the norm, Barrett had started training his nurses in special care for thoracic surgical patients.' 'Go and read medicine; it's the doctors who desert the dying and there's so much more to be learnt about pain' Barrett told Cicely Saunders and persuaded her to study medicine. Later Saunders founded the Hospice Movement and engaged in research, developing a new specialty for care of the terminally ill patient. $^{14}$

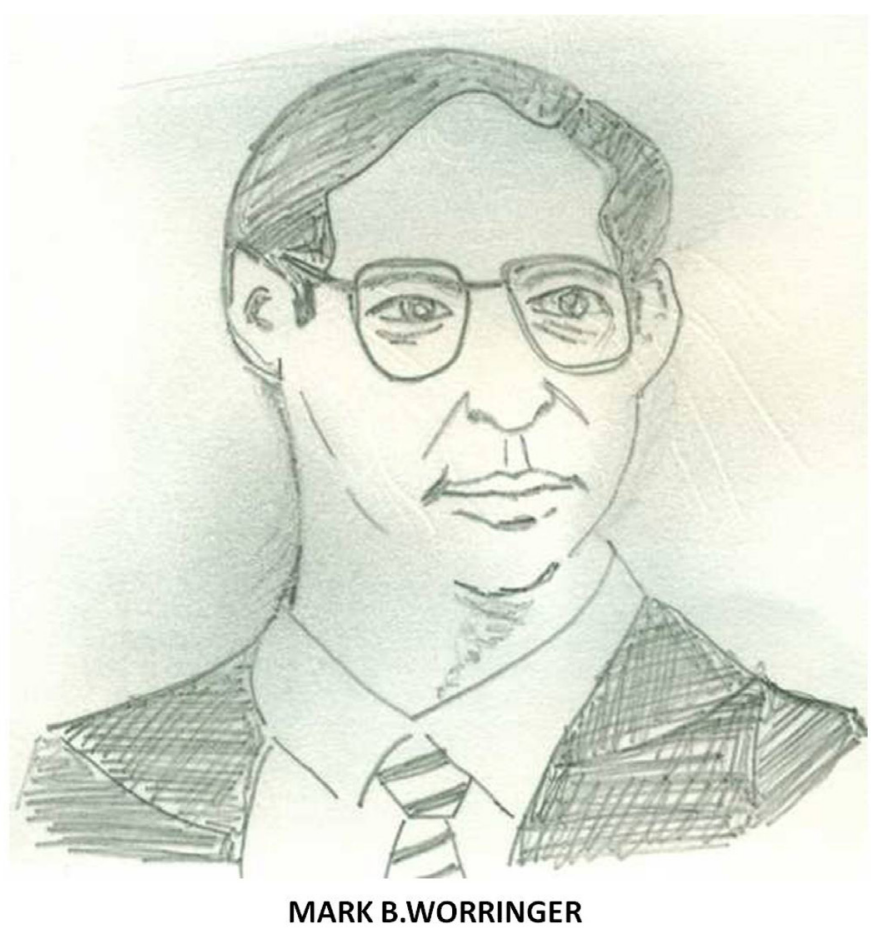

Sir Ronald Belsey, another eminent surgeon from England, has to behighlighted for his rigorous experimental attitude and adherence to publication ethics. Well-known for his Belsey Mark IV operation for gastroesophageal reflux disease, he was experimenting with several modules for constructing the best physiological antireflux mechanism and named them Marks I-III. Finally he was convinced with the 270 degree partial wrap and named it Mark IV. Nevertheless, he refused to publish the results until the clinical benefit was evident with long term follow-up. Later, his senior registrar published them after a 10-year follow up of patients..$^{15}$ Sir Ron Belsey, who had trained many of the late 20th Century esophageal surgeons like David Skinner, Griff Pearson and Marc Orringer, later conceded that Norman Barrett was very influential in kindling his interest in esophageal surgery. ${ }^{16}$

During the years when giants of esophageal surgery, like Sir Richard Sweet, Sir Ivor Lewis and Sir Ronald Belsey, were popularizing and perfectingtheir technique of transthoracic esophagectomy, a 35 year old surgeon was about to begin another revolution in esophageal surgery, presenting a paper entitled, 'Esophagectomy without Thoracotomy' at the 1978 American Association of Thoracic Surgeons (AATS) meeting in New Orleans. The young surgeon was Marc Orringer. Naef writes that 
'...the 45-min discussion following Orringer's talk will always remain a vivid memory of, maybe, the greatest 'show' in thoracic surgical history' and he recalls that Belsey started the discussion with the following remark on Orringer's paper, 'Essay on BLIND surgery and his expedition into the DARK AGES' and Griff Pearson concluding it with," If you have not tried this operation, don't knock it." ${ }^{\prime 6}$ In early 2013, during an interview before his retirement, Orringer recollects the stiff opposition he had to face at the inception of his technique and says, "I was a kid telling senior chest surgeons, 'You don't need to open the chest to remove the esophagus." 17

In an interview by James Luketich, Orringer reveals how he conceived the surgery of trans-hiatal esophagectomy. He would go to the autopsy room and perform the procedure several times on cadavers to prove that the stomach of Caucasians could reach the neck without any tension. ${ }^{18}$ His resolute and unshakeable faith in its principles and utility made him achieve less than $1 \%$ mortality rate for esophagectomy which had been around 20-30\% when he joined the department at Michigan. In 2007, his group had published in the Annals of Surgery, their data on 2007 esophagectomies from what was a mere 28 cases during 1978. ${ }^{19,20}$ Retiring as the Cameron Haight Collegiate Professor of Thoracic Surgery, Orringer says "I'm leaving with the sense of a job well done and grateful to an institution which has allowed my academic career to flourish." ${ }^{17}$ This bearsresemblance to what Mikulicz said shortly before he died in 1905,' I am dying without any regret and satisfied with my life. I have worked according to my strength and I found esteem and happiness in the world.' $^{21}$

\section{Conclusion}

Throughout the years, numerous surgeons have lived and retired. Nonetheless, only few, stand distinct and vivid in our memories. The common element that runs as a string in the necklace is their devotedness and scrupulousness, oblivious of the drudgery. However, life is multifarious and an elementary advice like 'work hard, you succeed' does not help to resolve the everyday problems a young surgeon faces. We firmly believe that knowledge of the personal and professional lives of eminent surgeons from our yesteryears will certainly provide a silent advice and a whispered solution to our day-to-day scrimmage.

\section{References}

1. Kazi RA, Peter RE. Christian Albert Theodor Billroth: master of surgery. J Postgrad Med. 2004;50(1):82-3

2. Kwan H, Mclaren R, Peterson T. The life and times of a great surgeon:Theodor Billroth (1829-1894). J Invest Surg. 2001;14:191-4.

3. Gawande A. SlowIdeas. The New Yorker(NYC). Available from: http://www.newyorker.com/ reporting/2013/07/29/130729fa_fact_gawande.

4. "What Life Means to Einstein: An Interview by George Sylvester Viereck" in The Saturday Evening Post. 1929;202:117.

5. Kielan W, Lazarkiewicz B, Grzebieniak Z, Skalski A, Zukrowski P. Jan Mikulicz-Radecki: one of the creators of world surgery. Keio J Med 2005;54(1):1-7

6. McCarthy OR. "The key to the sanatoria". J R Soc Med. 2001; 94(8): 413-7.

7. Ferdinand Sauerbruch (1875-1951) - Thoracic Surgeon. JAMA. 1964;190(2):152-153.

8. A.P. Naef. The mid-century revolution in thoracic and cardiovascular surgery: Part 1. Interact Cardiovasc Thorac Surg. 2003; 219-226.

9. Ellis H. Franz Torek (1861-1938): first successful resection of an oesophageal tumour. Br J Hosp Med (Lond). 2008;69(9):529

10. Lord RV. Norman Barrett, "doyen of esophageal surgery". Ann Surg. 1999;229(3):428-39.

11. Barrett NR. Publish or perish. J Thorac Cardiovasc Surg. 1962;44:167-179.

12. Obituary. Norman R. Barrett. The Times,11-19-1979.

13. Barrett NR. Foreign bodies in the cardiovascular system. Br J Surg 1950;37:416-445.

14. Saunders C. Preface. In: Saunders C, ed. The Management of Terminal Malignant Disease. London: Edward Arnold Publishers; 1978.

15. The Royal College of Surgeons of England Reg Charity no: 212808. Available from: http://livesonline.rcseng. ac.uk/biogs/E000447b.htm

16. A.P. Naef. The mid-century revolution in thoracic and cardiovascular surgery: Part 3. Interact Cardiovasc Thorac Surg. 2004;3-10.http://surgery.med.umich. edu/news/?p=2125 http://www.ctsnet.org/sections/ videosection/giants/2010Giants_OrringerMark 
17. Orringer MB, Sloan H. Esophagectomy without thoracotomy. J Thorac Cardiovasc Surg. 1978;76:643-654

18. Orringer MB, Marshall B, Chang AC, Lee J, Pickens A, Lau CL. Two thousand transhiatal esophagectomies: changing trends, lessons learned. Ann Surg. 2007;246(3):363-74.

19. Mikulicz J: Letter to Professor A. Private archive of Professor F. Anschu" tz (in German). Eiselberg 1905 June. 